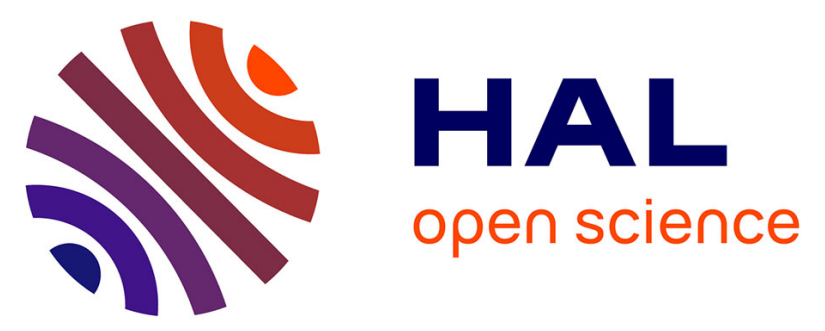

\title{
Controllable mesostructure, magnetic properties of soft magnetic Fe-Ni-Si by using selective laser melting from nickel coated high silicon steel powder
}

N. Kang, M. El Mansori, F. Guittonneau, H. Liao, Y. Fu, Emmanuel Aubry

\section{To cite this version:}

N. Kang, M. El Mansori, F. Guittonneau, H. Liao, Y. Fu, et al.. Controllable mesostructure, magnetic properties of soft magnetic Fe-Ni-Si by using selective laser melting from nickel coated high silicon steel powder. Applied Surface Science, 2018, 455, pp.736-741. 10.1016/j.apsusc.2018.06.045 . hal02416779

\author{
HAL Id: hal-02416779 \\ https://hal.science/hal-02416779
}

Submitted on 17 Dec 2019

HAL is a multi-disciplinary open access archive for the deposit and dissemination of scientific research documents, whether they are published or not. The documents may come from teaching and research institutions in France or abroad, or from public or private research centers.
L'archive ouverte pluridisciplinaire HAL, est destinée au dépôt et à la diffusion de documents scientifiques de niveau recherche, publiés ou non, émanant des établissements d'enseignement et de recherche français ou étrangers, des laboratoires publics ou privés. 


\title{
Controllable mesostructure, magnetic properties of soft magnetic Fe-Ni-Si by using selective laser melting from nickel coated high silicon steel powder
}

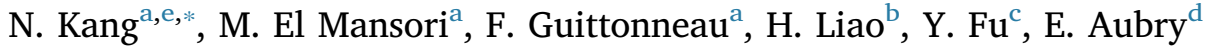 \\ a MSMP Laboratory, EA-7350, Arts et Métiers ParisTech, Aix-en-Provence, France \\ b ICB UMR 6303, CNRS, Univ. Bourgogne Franche-Comté, UTBM, F-90010 Belfort, France \\ ${ }^{c}$ Department of Materials Science and Engineering, Dalian Maritime University, 116026 Dalian, China \\ d Nipson Technology, Al des Marronniers, 90000 Belfort, France \\ e State Key Laboratory of Solidification Processing, Key Laboratory of Metal High Performance Additive Manufacturing and Innovative Design, MIIT china, Northwestern \\ Polytechnical University, Xi'an 710072, PR China
}

\author{
A B S T R A C T
}

Keywords:

Additive manufacturing

Selective laser melting

Soft magnetic materials

Anisotropic mesostructure
Fe-Ni-Si soft magnetic parts, using Ni coated high silicon steel powder, were manufactured by selective laser melting process. The type of defect changes from porosity to cracks and the relative density increases, from $50 \%$ to $99 \%$, with the decreasing laser scanning speed. The microstructural analyses indicate that the low laser scanning speed fully melted the nickel coating and high-silicon steel core. The EBSD study showed that the separated island and lamellar mesostructures appeared on the top and side view respectively. Moreover, no apparent texture were observed. The magnetization saturation of SLM processed sample decreased, as the laser scanning speed was increased. Consequently, the magnetic properties of SLM processed Fe-Ni-Si alloy also showed anisotropic feature in building and scanning directions, which can be attributed to their different mesostructure.

\section{Introduction}

Selective laser melting (SLM), a powder-bed additive manufacturing (AM) process, is relatively a new near net-shaped AM process with high dimensional producing accuracy. In this process, the 3D computeraided design (CAD) model is created and then virtually sliced into thin layers with typical (from several micrometers to hundreds micrometers) layer thickness. The component is built layer by layer with a controlled high energy laser beam from the powder feedstock [1-3]. As one kind of material processing technology, the parameter-defect-microstructure relation during SLM plays a vital role in the extended potential applications. Kasperovich et al. [4] investigated the correlation between porosity and processing parameters in SLM processed TiAl6V4 and indicates that the defect can be defined as two dominant types based in the energy density. In general, the laser input energy density could be controlled by process parameters such as laser power scanning speed, layer thickness, and so forth. Moreover, Qi et al. [5] reported that the defocusing distance has a significant effect on the melting mode, which presents nonnegligible influence on the microstructural and mechanical properties. Furthermore, the solidification behavior during SLM process was studied by Acharya et al. [6] with the IN718 powder and concluded that the dimension and temperature gradient in the molten pool affect the microstructural and mechanical properties of the SLM processed components.

Given to its high permeability, low coercivity, and low hysteresis loss, the soft ferromagnetic material is usually used to amplify the flux density generated by a magnetic field [7]. For example, the silicon steel presents superior soft magnetic properties, which is suitable to produce the iron core of the motors [8]. Conventionally, the silicon steel is prepared into a sheet by using several cold and hot rolling followed by annealing to get oriented grains with the Goss texture (cube-on-edge) obtaining low magnetic loss and then machined to the desirable form [9]. The magnetic properties, such as magnetostriction, suppresses magneto-crystalline anisotropy, and so forth., could be improved by high silicon content, which is favor of high performance soft magnetic materials. In contrast, the ductility of silicon steel decreases significantly as the silicon content increases, for eg. Fe-6.5 wt\% Si with near zero ductility. Thus, it significantly limits its potential application due to the small machining process window [10]. Up to now, the high silicon steel (over $3 \mathrm{wt} \%$ ) could be manufactured by melt spinning [11,12], chemical vapor deposition [13], spraying forming [14] and thermal spraying [15]. However, all of these technologies show limitations on the production of any complex component. Considering the structure of silicon steel sheet, the layer by layer manufacturing, AM,

\footnotetext{
* Corresponding author at: MSMP-Arts et Métiers Paristech, 2, Cours des Arts et Métiers, 13617 Aix-en-Provence, France.

E-mail address: nan.kang@ensam.eu (N. Kang).
} 


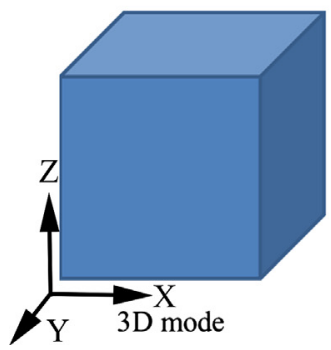

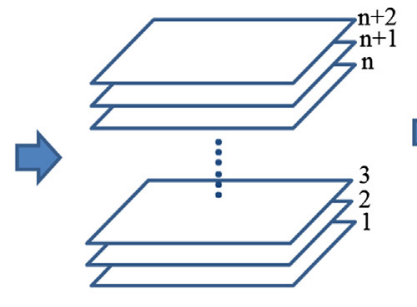

2D layer

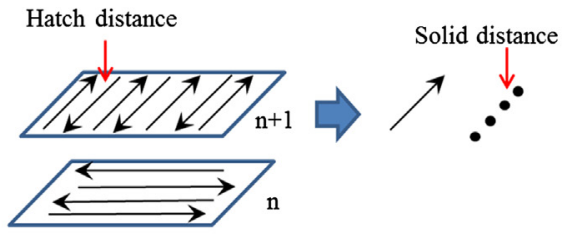

Two layers one single trace

Fig. 1. Building processing and scanning mode of SLM process (Z: building direction (BD), X: scanning direction $\left(\mathrm{SD}_{\mathrm{X}}\right)$, $\mathrm{Y}$ : $s c a n n i n g$ direction $\left(\mathrm{SD}_{\mathrm{Y}}\right)$ ).
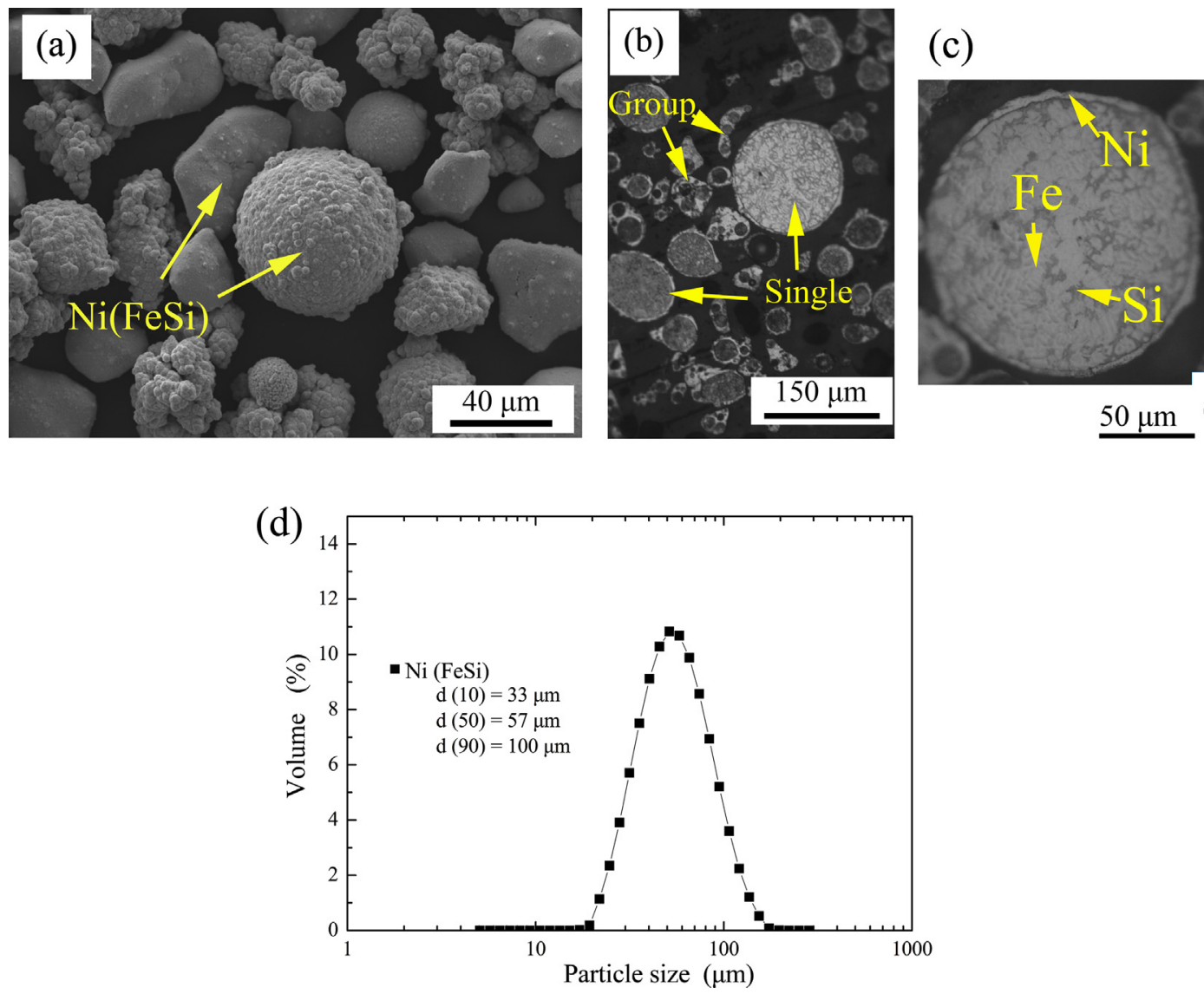

Fig. 2. (a) Surface morphologies, (b) and (c), cross-sections and (d) particle size distribution of nickel coated high silicon steel powder.

could be an efficient net-shaped process for the high-silicon steel. Recently, Garibaldi et al. [16-18] have investigated the SLM processed high silicon steel and indicated that this process could be one of the promising methods to manufacture the soft magnetic component with complex morphology. Additionally, Zhang et al. [19] did the parametrical analysis with the SLM processed Fe-Ni alloys for obtaining high relative density component. Fe-Ni intermetallics, such as $\mathrm{FeNi}_{3}$, are considered as another essential soft magnetic material. The ternary Fe-Ni-Si soft magnetic parts [20-22] were manufactured by SLM using nickel coated high silicon steel powder. The coated commercial powder combines the advantages of chemical homogeneity and low cost, compared with the pre-alloyed powder and powder mixture.

\section{Experimental}

The cubic samples, $8 \times 8 \times 8 \mathrm{~mm}^{3}$, were produced using an MCPrealizer SLM 250 equipment (MCP-HEK Tooling GmbH, Germany) equipped with an Nd-YAG fiber laser with a spot size of $40 \mu \mathrm{m}$ and maximum power of $400 \mathrm{~W}$. This system employs a hopper of feedstock powder. In order to obtain high production efficiency and controllable mesostructure, the laser power, hatch distance, and layer thickness were fixed at $300 \mathrm{~W}, 120 \mu \mathrm{m}$ and $50 \mu \mathrm{m}$ respectively. Laser scanning speed ranged from 0.5 to $6 \mathrm{~m} / \mathrm{s}$. The laser path rotation between two adjacent layers was $90^{\circ}$. The building processing and scanning mode are shown in Fig. 1. It can be seen that the cubic sample consists of layers with a thickness of $50 \mu \mathrm{m}$, and laser scanning realizes each layer with hatch distance of $120 \mu \mathrm{m}$. Moreover, the laser discontinuous moved with solid distance of $120 \mu \mathrm{m}$ during the laser melting process. Thus, the scanning speed was controlled by the exposure time from the equation:

$v=\frac{\text { Solid distance }}{\text { exposure time }}$

\subsection{Materials characterization}

The relative density was measured by an image analysis method. The phases of SLM processed samples were characterized by X-ray 

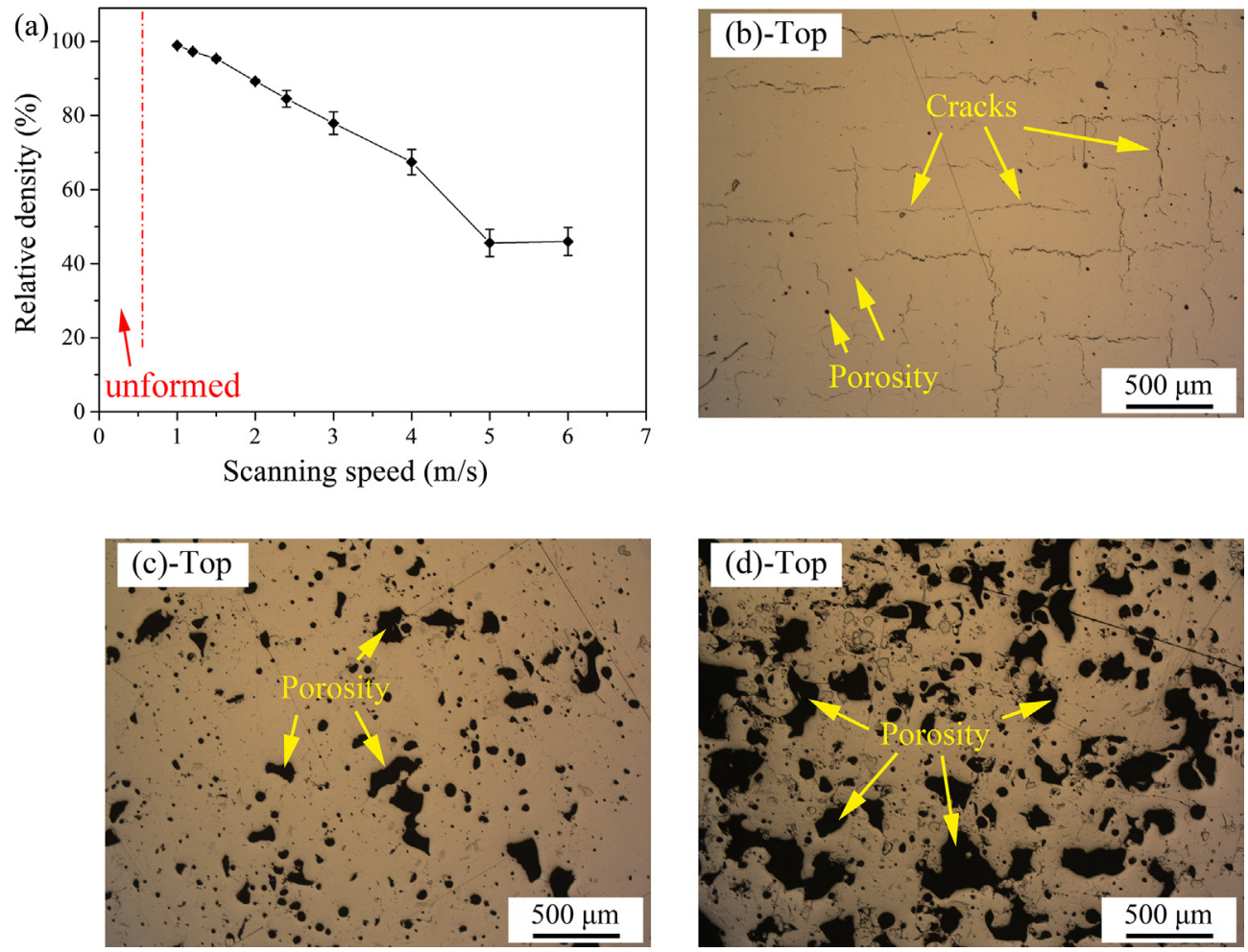

Fig. 3. (a) The relative density of SLM processed Fe-Ni-Si alloys and defects morphologies of SLM processed sample at laser scanning speed of (b) $1 \mathrm{~m} / \mathrm{s}$, (c) $2 \mathrm{~m} / \mathrm{s}$ and (d) $4 \mathrm{~m} / \mathrm{s}$.

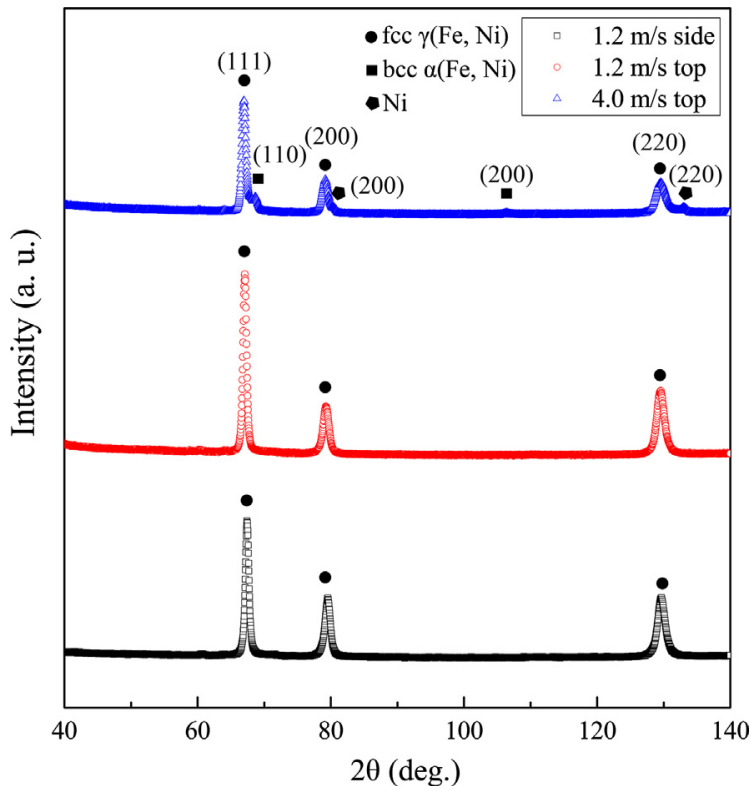

Fig. 4. XRD patterns of SLM processed Fe-Ni-Si alloys at several laser scanning speeds ( 1.2 and $4.0 \mathrm{~m} / \mathrm{s}$ ) and several cross-sections (top and side view).

diffraction with scanning speed about of $1^{\circ} / \mathrm{min}$. The microstructure was studied by a Scanning Electron Microscope (SEM JEOL-5900 LV, Japan) equipped with X-ray energy dispersive spectroscopy (EDS). Electron backscattered diffraction (EBSD) analyses were performed on a JEOL JSM-7001F fitted with an HKL Nordlys camera from Oxford Instruments and controlled by CHANNEL5 software suite, as Flamenco for acquisition. The two maps were acquired at $20 \mathrm{kV}$, probe current 16 (a.u.), magnification $\times 100$, working distance $20 \mathrm{~mm}$, camera gain low, binning $4 \times 4$ pixels, averaging six images, Hough resolution 70, step size $1.7 \mu \mathrm{m}$, grid size $700 \times 500$ points. Maps were extrapolated at the five neighbors' level in Tango; inverse pole figures were constructed in Mambo software. The magnetic measurements were performed by using a hysteresimeter Bull M2000/2010, which allowed to measure coercivity and saturation magnetization. The magnetic properties were measured from three different directions, $\mathrm{X}, \mathrm{Y}$, and $\mathrm{Z}$ (see in Fig. 1).

\subsection{Powder characterizations}

The high-silicon steel powder $(0.5 \mathrm{Ni6.5Si93.0Fe} \mathrm{wt. \% )} \mathrm{was} \mathrm{pre-}$ pared by gas atomization and then coated pure nickel by using hydrometallurgy (Institute of Process Engineering, Chinese Academy of Sciences). From Fig. 2(a), it can be seen that the nickel coated high silicon steel powder presents particulate morphologies in two types: (1) smooth surface (irregular form) (2) rough surface (spherical form). Furthermore, the microstructures of powder cross section are illustrated in Fig. 2(b). It can be observed that the particle with smooth surface is formed by a group of small high silicon steel powders and then covered by nickel. The rough surface appears on the large spherical high-silicon steel particle. Image with high magnification of Ni-coated large high silicon steel powder is shown in Fig. 2(c). No clear diffusion layer was observed from the cross section microstructure (Fig. 2(b and c)). Due to the Ni content fluctuation for each particle, the nickel content was measured by image analysis for around hundreds of particles from three picture of powder bed, which is average about of $43( \pm 5)$ wt. \%. The measured error is the average of variance from 3 pictures. The laser diffraction particle size test indicated the powder presented a mean size of about $57 \mu \mathrm{m}$ with a normal distribution (see in Fig. 2(d)).

\section{Results and discussion}

\subsection{Densification and phase analysis}

The relative density of sample prepared with several laser scanning speeds ranged from 0.5 to $6 \mathrm{~m} / \mathrm{s}$ is shown in Fig. 3(a). For the sample obtained at laser scanning speed of $0.5 \mathrm{~m} / \mathrm{s}$, due to the high input 
(a)

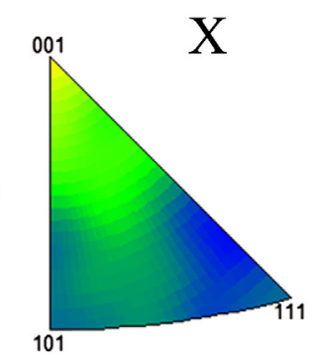

(b)

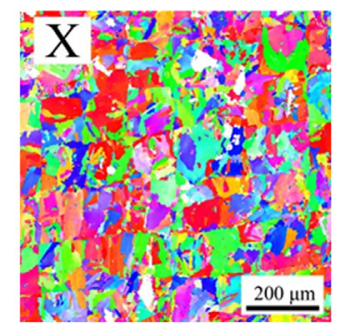

(c)

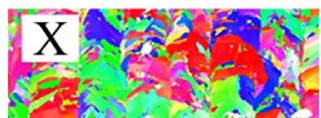

(d)
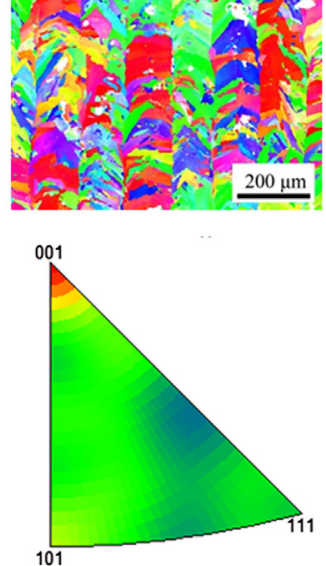
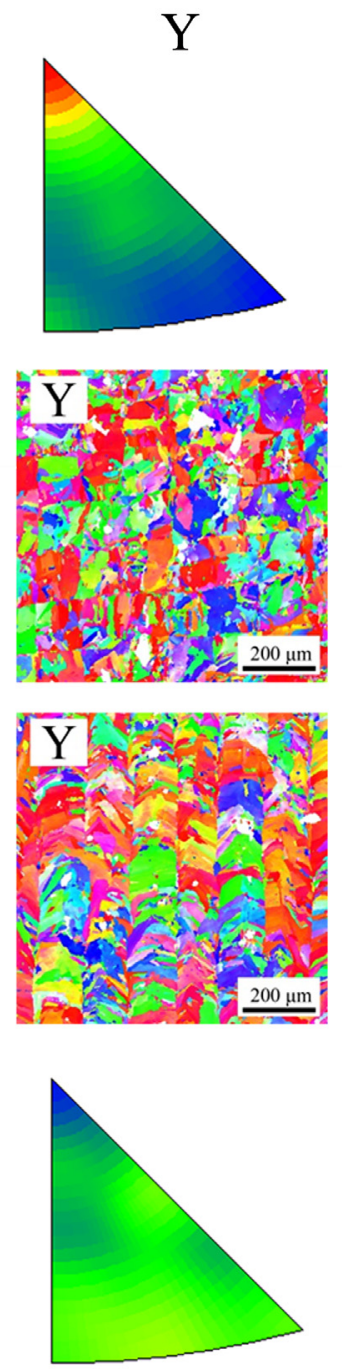
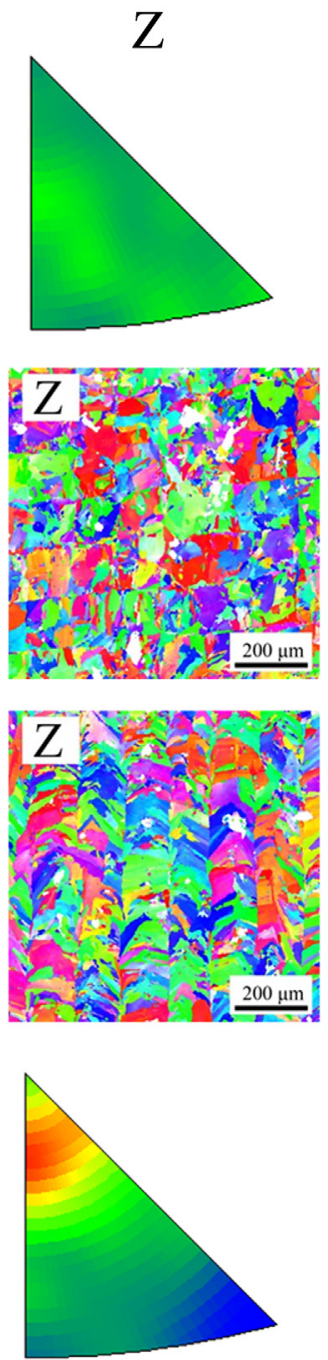
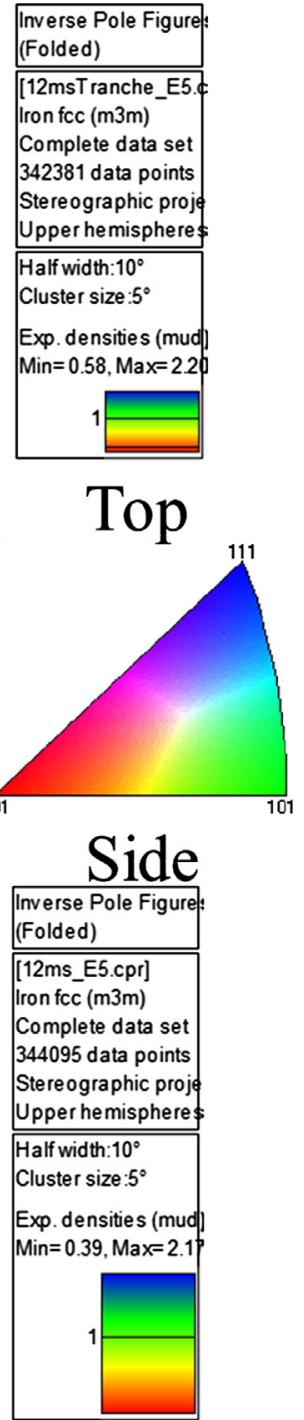

Fig. 5. (a, d) Inverse pole figures and (b, c) EBSD orientation maps of SLM processed Fe-Ni-Si alloy from side and top views respectively in the three directions.
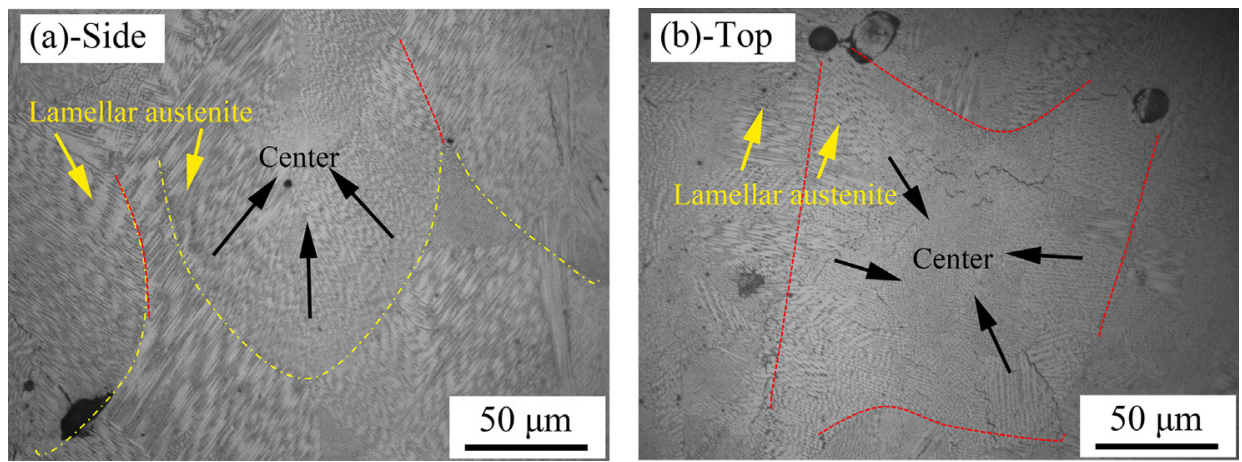

Fig. 6. The microstructures (after etching) of SLM processed Fe-Ni-Si alloys at laser scanning speed $1.2 \mathrm{~m} / \mathrm{s}$ of (a) side and (b) top cross-sections. (yellow line: molten pool boundary; red line: lamellar austenite interfaces). (For interpretation of the references to colour in this figure legend, the reader is referred to the web version of this article.)

energy and fragile mechanical properties, the cubic sample cannot be prepared successfully. The sample processed at laser scanning speed of $1 \mathrm{~m} / \mathrm{s}$ presents the highest relative density about of $99 \%$. As the laser scanning speed increases from 1 to $6 \mathrm{~m} / \mathrm{s}$, the relative density continually decreases from $99 \%$ to $50 \%$, which is similar to the work of Qiu et al. [23] in case of SLM processed invar alloys. Moreover, the OM images corresponding to SLM processed samples in laser scanning speed of 1,2 , and $4 \mathrm{~m} / \mathrm{s}$ are shown in Fig. 3(b-d). The cracks appear in the sample fabricated at low scanning speed (see in Fig. 3(b)), causing low ductility of high-silicon steel and high energy input. The similar result is also reported by Garibaldi et al. [17], indicated that the high energy input causes the low cooling rate of the molten pool. Moreover, in SLM process, the thermal gradient in the molten pool also acts as a source for crack during the solidification [5]. As the laser scanning speed rises, the large irregular porosity appears instead of micro-crack. According to the report of Kasperovich et al. [4], the high laser scanning speed (low energy density) leads to large irregular porosity due to insufficient energy input. Moreover, the cracks can be observed at the interfacial 
Table 1

Magnetic properties of SLM processed Fe-Ni-Si alloys at laser scanning speed of $1.2 \mathrm{~m} / \mathrm{s}, 2 \mathrm{~m} / \mathrm{s}$ and $4 \mathrm{~m} / \mathrm{s}$.

\begin{tabular}{llll}
\hline Scanning speed $(\mathrm{m} / \mathrm{s})$ & 1.2 & 2 & 4 \\
\hline Mass $(\mathrm{g})$ & 3.0 & 2.3 & 2.1 \\
Porosity (\%) & $2.7 \%$ & $10.8 \%$ & $32.6 \%$ \\
$\mathrm{Ms}(\mathrm{emu} / \mathrm{g})$ & $91.8 \pm 0.7$ & $91.2 \pm 0.3$ & $85.4 \pm 0.8$ \\
$\mathrm{Mr}(\mathrm{emu} / \mathrm{g})$ & $1.02 \pm 0.02$ & $1.17 \pm 0.02$ & $1.34 \pm 0.02$ \\
$\mathrm{Hc}(\mathrm{Oe})$ & $27 \pm 1$ & $28 \pm 0$ & $27 \pm 0$ \\
$\mathrm{~S}(\%)$ & $1.10 \pm 0.03$ & $1.30 \pm 0.03$ & $1.60 \pm 0.04$ \\
\hline
\end{tabular}
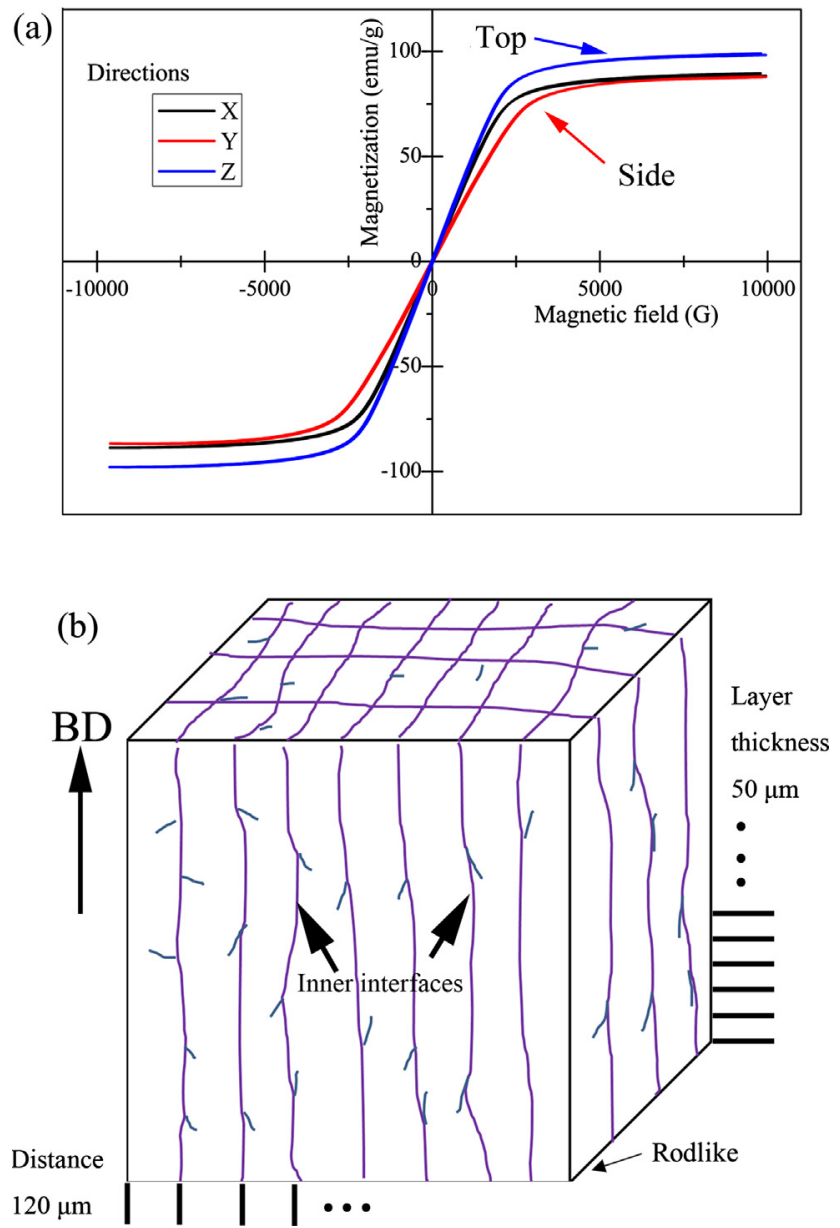

Fig. 7. (a) Series of hysteresis loops of SLM processed Fe-Ni-Si alloys with laser scanning speed and (b) the schematic illustration of mesostructure.

regions between rod-like structures, which can be attributed to the weak bonding strength between laser tracks.

The XRD patterns of SLM processed Fe-Ni-Si alloys are shown in Fig. 4. The sample manufactured at high scanning speed $(4.0 \mathrm{~m} / \mathrm{s})$ presents a phase mixture, composed of fcc $\gamma(\mathrm{Fe}, \mathrm{Ni}), \mathrm{bcc} \alpha(\mathrm{Fe}, \mathrm{Ni})$ and nickel phase. Qiu et al. [23] reported the appearance of fcc $\gamma$ (Fe, Ni) and bcc $\alpha$ (Fe, Ni) in case of SLM processed invar alloy as the result of rapid solidification of SLM process. In this study, the Fe and Ni possessed the similar composition ratio. Thus, both $\gamma(\mathrm{Fe}, \mathrm{Ni})$ and $\alpha(\mathrm{Fe}, \mathrm{Ni})$ appeared in the SLM sample at high laser scanning speed. As the laser scanning speed decreased to $1.2 \mathrm{~m} / \mathrm{s}$, the partial melted Ni coating was fully melted, and only fcc $\gamma(\mathrm{Fe}, \mathrm{Ni})$ was observed in XRD pattern due to the decreased cooling rate $[20,21]$. On the other hand, the XRD patterns from the top and side views of SLM processed dense sample $(1.2 \mathrm{~m} / \mathrm{s})$ are also illustrated in Fig. 4. From the point view of phase composition, the two sides present the same fcc $\gamma(\mathrm{Fe}, \mathrm{Ni})$ phase. However, the intensity of phase's peak is different, in details, the intensity ratio between (1 111 ) plane and (200) plane of top view is higher than that of the side view. It indicates that the preferred orientation of $\gamma(\mathrm{Fe}, \mathrm{Ni})-$ (1 111 ) plane of top-section is slightly stronger than that of side-section. A further EBSD analysis is shown in Fig. 5.

\subsection{Microstructure}

During the SLM process, the surroundings, for example, the thermal conductivity of powder and solidified material near the molten pool, affects the temperature gradient significantly. Therefore, the heat conduction in building direction is higher than that of spatial directions. It causes anisotropy in both microstructure and mechanical/ physical properties. The EBSD images and analysis results from both side and top views in consideration of industrial requirement (speed $1.2 \mathrm{~m} / \mathrm{s}$ ) are shown in Fig. 5. Fig. 5(b) and (c) represent orientation maps of "inverse pole figure" type, while Fig. 5(a) and (d) represents inverse pole figures, with a stereographic projection. The top view EBSD maps present the island microstructure weaved by laser scanning in $X$ and $Y$ directions, Fig. 5(b). Each square has a side length of $120 \mu \mathrm{m}$, which correspond to the hatch distance during SLM process. The EBSD maps of side view indicate a lath-shaped microstructure parallel to the BD with a bandwidth of $120 \mu \mathrm{m}$, which well corresponds to the hatch distance, too (see in Fig. 5(c)).

Random colors in orientation maps and very low maximum densities $(\sim 2.2$ mud) in IPF for both top and side views indicate the absence of texture in the material. Also, grain boundaries are random, and no particular boundary (like coincidence site lattice, CSL, e.g., $\Sigma 3$ ) had been created during the process. On the grain shape, the grains viewed from the top appear much more round or square (low ratio between high diameter and small diameter of the fitted ellipse) while the grains seen from the side seem much more elongated (higher ratio between high diameter and small diameter of the fitted ellipse). On the grain size (considering a grain diameter $>6 \mu \mathrm{m}$, i.e., 10 pixels, and a grain boundary threshold of $5^{\circ}$ ), for top view $\bar{d}=14.8 \mu \mathrm{m}, \sigma=12.3 \mu \mathrm{m}$, $\mathrm{N}=3274, \operatorname{Max}=137 \mu \mathrm{m}$; for side view $\bar{d}=15.9 \mu \mathrm{m}, \sigma=13.9 \mu \mathrm{m}$, $\mathrm{N}=2750, \quad \mathrm{Max}=157 \mu \mathrm{m}$. Finally, kernel average misorientation (KAM) values for a $7 \times 7$ size grid are low in the two measurements (peak center at about $0.7^{\circ}$ ) which indicate the material is not deformed.

The chemical etched (Nital) microstructure of SLM processed dense part from the side, and top views are shown in Fig. 6. From both images, it can be observed a mixed structure consists of cellular austenite and lamellar austenite. The cellular austenite appears mainly in the central region of the molten pool due to the low cooling rate without distinct thermal gradient. In contrast, the lamellar austenite can be observed near the boundary of the molten pool with grow direction to center [24], which can be attributed to the higher thermal conductivity of dense previous fabricated layer than that of meal liquid and powder. Moreover, the interface between the lamellar austenite of two contacted molten pools, which is indicated by the red line, is the high-angled grain boundary. As shown in Fig. 6(a), their accumulations by side view lead to the formation of lamellar structure. Meanwhile, the island structure in EBSD, which can be seen Fig. 5, is the result of top view accumulation (see in Fig. 6(b) by the red line).

\subsection{Magnetic properties}

The average values of magnetization saturation (Ms), residual magnetization (Mr) and coercivity (Hc) of SLM processed Fe-Ni-Si with laser scanning speed of $1.2 \mathrm{~m} / \mathrm{s}, 2 \mathrm{~m} / \mathrm{s}$, and $4 \mathrm{~m} / \mathrm{s}$ are summarized in Table 1. Meanwhile, the ratios between Ms and Mr, which presents the soft magnetic properties, were also calculated and shown as $S$ in Table 1. Firstly, it can be observed that the soft magnetic properties (S) of SLM processed sample gradually become worse, as the laser scanning speed increases from $1.2 \mathrm{~m} / \mathrm{s}$ to $4 \mathrm{~m} / \mathrm{s}$. This trend can be attributed to two factors: (1) macro-structural effect and (2) crystallography effect. Moreover, Ms is defined as magnetization saturation per gram, that is to 
say, the effect of relative density was eliminated. However, the appearance of pores influences the microstructure of SLM processed sample. Igarashi et al. [25] investigated the effect of porosity on magnetic properties and reported that the demagnetization is proportion to the porosity. For the second factor, in general, Ms of the magnetic material decreases as the grain size decreases [25]. In SLM process, the higher laser scanning speed (low energy input), the smaller molten pool with the results of higher cooling rate [26]. So the sample prepared at high scanning speed tends to possess ultra-fine or metastable microstructure, which presents small Ms. Additionally, the unmelted nickel coating in the sample obtained at high laser scanning speed also causes a decrement of Ms. Lastly, from Table 1, it can be seen that the coercivity is independent of laser scanning speed. According to the work of Igarashi et al. [25], the porosity illustrates no influence on coercivity. Unfortunately, the reasons for stable coercivity of SLM processed Fe-Ni$\mathrm{Si}$ alloys are not precise and more work will be performed in the future.

On the other hand, the hysteresis loops of SLM processed dense FeNi-Si sample $(1.2 \mathrm{~m} / \mathrm{s}$ ) along three different directions $\mathrm{X}$ and $\mathrm{Y}$ (scanning direction) and $\mathrm{Z}$ (build direction), Fig. 7, which illustrates the anisotropic magnetic properties in different measured directions. For instance, the $\mathrm{Ms}$ in $\mathrm{Z}$ direction is higher than that of $\mathrm{X}$ and $\mathrm{Y}$ directions. In general, to reduce the induced eddy current, the silicon steel is manufactured in the form of a sheet. In this work, as shown in Fig. 5(b), the SLM processed Fe-Ni-Si sample presents an in-situ lamellar microstructure from the side views and island microstructure from the top view. Therefore, the 3D structure of SLM processed sample can be schematically illustrated in Fig. 7(b). In general, a very common magnetizing direction is the axis of the part [27]. Due to this anisotropic structure of SLM processed sample, consequently, the magnetic properties present also anisotropic feature. On the other hand, as shown in Fig. 5, no texture can be determined in the SLM processed sample. Furthermore, the porosity/crack distribution, ordering in the microstructure and residual stress distribution [28] have influence on magnetic properties. This work proposed that the rod-like mesostructured may be another important factor on the anisotropic magnetic properties. Unfortunately, the synergistic effect of those factor is still an open question. Plus work will be carried out to investigate the effect of each factor on magnetic properties. Additionally, during the SLM process, the rod-like mesostructure can be successfully controlled by process parameters, e.g., hatch distance. So, the in-situ formation of the separated structure by SLM with desirable mesostructure could be an effective way to produce the soft magnetic Fe-Ni-Si system.

\section{Conclusion}

The dense Fe-Ni-Si soft magnetic alloy was manufactured by SLM process from nickel coated high silicon steel powder.

(1) With the increment of energy input, the porosity can be nearly eliminated. However, the cracks appear in the low porosity sample due to the low ductility of Fe-Ni-Si alloys.

(2) Only the fcc $\gamma(\mathrm{Fe}, \mathrm{Ni})$ can be observed in XRD pattern of the SLM processed sample with laser scanning speed of $1.2 \mathrm{~m} / \mathrm{s}$. Moreover, the dense part presents a separated lamellar microstructure with low texture content from the side view.

(3) This in-situ manufactured rod-like structure could be an important reason for the anisotropic magnetic properties in XOY and XOZ/ YOZ sections, which should be considered as an essential factor in the design of soft magnetic component with complex morphology.

(4) In general, the magnetization saturation presents a negative correlation with laser scanning speed, which can be attributed to macro-structure and crystallography. As the laser scanning speed increases from 1 to $4 \mathrm{~m} / \mathrm{s}$, the coercivity remains constant about 27 Oe.

\section{References}

[1] D. Gu, C. Ma, M. Xia, D. Dai, Q. Shi, A multiscale understanding of the thermodynamic and kinetic mechanisms of laser additive manufacturing, Engineering 3 (2017) 675-684.

[2] P. Wei, Z. Wei, Z. Chen, J. Du, Y. He, J. Li, Y. Zhou, The AlSi10Mg samples produced by selective laser melting: single track, densification, microstructure and mechanical behavior, Appl. Surf. Sci. 408 (2017) 38-50.

[3] N. Kang, P. Coddet, H. Liao, T. Baur, C. Coddet, Wear behavior and microstructure of hypereutectic Al-Si alloys prepared by selective laser melting, Appl. Surf. Sci. 378 (2016) 142-149.

[4] G. Kasperovich, J. Haubrich, J. Gussone, G. Requena, Correlation between porosity and processing parameters in $\mathrm{TiAl}_{6} \mathrm{~V}_{4}$ produced by selective laser melting, Mater. Des. 105 (2016) 160-170.

[5] T. Qi, H. Zhu, H. Zhang, J. Yin, L. Ke, X. Zeng, Selective laser melting of Al7050 powder: melting mode transition and comparison of the characteristics between the keyhole and conduction mode, Mater. Des. 135 (2017) 257-266.

[6] R. Acharya, J.A. Sharon, A. Staroselsky, Prediction of microstructure in laser powder bed fusion process, Acta Mater. 124 (2017) 360-371.

[7] S. Chikazumi, Physics of Ferromagnetism, secnd ed., Clarendon Press, Oxford, 1997.

[8] W. Chen, J. Liu, Z. Cheng, X. Lin, J. Zhu, Effect of chromium on microstructure, ordered phase and magnetic properties of Fe- $6.5 \mathrm{wt} \% \mathrm{Si}$ alloy, Mater. Today Proc. 2 (2015) S314-S318.

[9] J.A. Sandoval Robles, A. Salas Zamarripa, M.P. Guerrero Mata, J. Cabrera, Texture evolution of experimental silicon steel grades. Part I: hot rolling, J. Magn. Magn. Mater. 429 (2017) 367-371.

[10] Y.F. Liang, J.P. Lin, F. Ye, Y.J. Li, Y.L. Wang, G.L. Chen, Microstructure and mechanical properties of rapidly quenched Fe-6.5wt.\% Si alloy, J. Alloys Compd. 504 (2010) S476-S479.

[11] K.I. Arai, N. Tsuya, Ribbon-form silicon-iron alloy containing around 6.5 percent silicon, IEEE Trans. Magn. 16 (1980) 126-129.

[12] T. Watanabe, H. Fujii, H. Oikawa, K.I. Arai, Grain boundaries in rapidly solidified and annealed Fe-6.5 mass\% Si polycrystalline ribbons with high ductility, Acta Metall. 37 (1989) 941-952.

[13] X.D. He, X. Li, Y. Sun, Microstructure and magnetic properties of high silicon electrical steel produced by electron beam physical vapor deposition, J. Magn. Magn. Mater. 320 (2008) 217-221.

[14] R.D. Cava, W.J. Botta, C.S. Kiminami, M. Olzon-Dionysio, S.D. Souza, A.M. Jorge Jr., C. Bolfarini, Ordered phases and texture in spray-formed Fe-5 wt\% Si, J. Alloys Compd. 509 (2011) 260-264.

[15] N.E. Fenineche, M. Cherigui, H. Aourag, C. Coddet, Structure and magnetic properties study of iron-based thermally sprayed alloys, Mater. Lett. 58 (2004) 1797-1801.

[16] J.N. Lemke, M. Simonelli, M. Garibaldi, I. Ashcroft, R. Hague, M. Vedani, R. Wildman, C. Tuck, Calorimetric study and microstructure analysis of the orderdisorder phase transformation in silicon steel built by SLM, J. Alloys Compd. 722 (2017) 293-301.

[17] M. Garibaldi, I. Ashcroft, M. Simonelli, R. Hague, Metallurgy of high-silicon steel parts produced using Selective Laser Melting, Acta Mater. 110 (2016) 207-216.

[18] M. Garibaldi, I. Ashcroft, J.N. Lemke, M. Simonelli, R. Hague, Effect of annealing on the microstructure and magnetic properties of soft magnetic Fe-Si produced via laser additive manufacturing, Scr. Mater. 142 (2018) 121-125.

[19] B. Zhang, N.E. Fenineche, H. Liao, C. Coddet, Magnetic properties of in-situ synthesized FeNi3 by selective laser melting Fe-80\%Ni powders, J. Magn. Magn. Mater. 336 (2013) 49-54.

[20] O. Ikeda, Y. Himuro, I. Ohnuma, R. Kainuma, K. Ishida, Phase equilibria in the Ferich portion of the Fe-Ni-Si system, J. Alloys Compd. 268 (1998) 130-136.

[21] W.W. Zhang, H.H. Xu, J.L. Liang, W. Xiong, Y. Du, Phase equilibria of the Fe-Ni-Si system at $850{ }^{\circ} \mathrm{C}$, J. Alloys Compd. 481 (2009) 509-514.

[22] U.C. Özöğüt, A. Çakır, Investigation of temperature dependent magnetization and elastic modulus in Si-doped Fe 65 Ni 35 invar alloys, J. Alloys Compd. 705 (2017) $126-130$.

[23] C. Qiu, N.J.E. Adkins, M.M. Attallah, Selective laser melting of Invar 36: microstructure and properties, Acta Mater. 103 (2016) 382-395.

[24] N. Kang, C. Verdy, P. Coddet, Y. Xie, Y. Fu, H. Liao, C. Coddet, Effects of laser remelting process on the microstructure, roughness and microhardness of in-situ cold sprayed hypoeutectic Al-Si coating, Surf. Coat. Technol. 318 (2017) 355-359.

[25] H. Igarashi, K. Okazaki, Effects of porosity and grain size on the magnetic properties of NiZn ferrite, J. Am. Ceram. Soc. 60 (1977) 51-54.

[26] T. Niendorf, S. Leuders, A. Riemer, H.A. Richard, T. Tröster, D. Schwarze, Highly anisotropic steel processed by selective laser melting, Metall. Mater. Trans. B Process Metall. Mater. Process. Sci. 44 (2013) 794-796.

[27] R. Hilzinger, W. Rodewald, Magnetic Materials: Fundamentals, Products, Properties, Applications, Publicis Publishing, Erlangen, 2013. 